\title{
Efek Dexmedetomidine 0,2 ug/kgbb Intravena terhadap Insiden Delirium saat Pulih Sadar dari Anestesi Umum pada Pasien Pediatrik
}

\section{The Effect of Dexmedetomidine 0,2 ug/kgBB Intravenous to Incidence of Awakening Delirium from General Anesthesia in Pediatric Patients}

\author{
Cahya Hendrawan*, Syafri Kamsul Arif* \\ *Bagian Anestesiologi, Perawatan Intensif dan Manajemen Nyeri Fakultas Kedokteran Universitas Hasanuddin,
}

\begin{abstract}
Background : Dexmedetomidine gives sedation effect, analgesic and anxiolitik after intravenous administration. Isoflurane and Sevoflurane associated with delirium effect when awakening from general anesthesia. This research using placebo as control, we evaluate delirium effect from single dose dexmedetomidine when awakening from general anesthesia with Isoflurane as inhalation agent in pediatric patients whom undergo elective operation.

Method: This is a double blind research. There are 46 children (age 3-10 years old) selected randomly had dexmedetomidin $0,2 \mathrm{ug} / \mathrm{kg}$ weight or placebo before the surgery ended. One hour after surgery, we evaluate delirium score. We noted ekstubation time, awakening, and side effect from dexmedetomidin. We also asessed post operative pain using objective pain scale (OPS).
\end{abstract}

Result: The delirium effect when awakening from general anesthesia in the group given dexmedetomidine are better than the placebo group $(P<0,05)$. Post operative pain are similar in both groups. Ekstubation time and awakening time in Dexmedetomidin group are longer than placebo group, but not qualified statistically. No side effect (hypotension and bradicardia) in both groups.

Conclusion: We conclude that dexmedetomidine 0,2 ug/ $\mathrm{kgBB}$ intravenous proven to minimize delirium incidens when awakening from general anesthesia with isoflurane with childen undergo elective surgery.

Keyword: dexmedetomidine, delirium, isofluran, anesthesia

\section{ABSTRAK}

Latar Belakang: Dexmedetomidine memberikan efek sedasi, analgesia, dan anxiolitik setelah pemberian intravena. Isofluran dan sevofluran dihubungkan dengan angka kejadian delirium saat pulih sadar dari anestesi umum pada pasien pediatrik. Pada penelitian dengan menggunakan placebo sebagai kontrol, kami mengevaluasi efek dari dosis tunggal dexmedetomidine pada delirium saat pulih sadar dari anestesi umum 
pada pasien pediatrik yang menjalani pembedahan elektif menggunakan anestesi umum dengan isofluran.

Metode: Pada penelitian acak tersamar ganda ini , 46 anak (usia 3-10 tahun) dipilih secara acak mendapatkan dexmedetomidin $0,2 \mathrm{ug} / \mathrm{kgBB}$ atau placebo pada akhir pembedahan. Semua pasien mendapatkan obat anestesi yang standar. Setelah pembedahan, nilai delirium saat pulih sadar dari anestesi umum diukur sampai 1 jam pascabedah. Waktu ekstubasi, waktu pulih sadar, dan efek samping dari dexmedetomidine dicatat. Setelah pembedahan nyeri pasien diukur dengan menggunakan objective pain scale (OPS).

Hasil: Nilai delirium saat pulih sadar dari anestesi umum pada kelompok dexmedetomidine lebih baik daripada kelompok placebo $(P<0,05)$. Nilai nyeri sama pada kedua kelompok (P>0,05). Waktu ekstubasi dan waktu pulih sadar lebih panjang pada kelompok dexmedetomidin tetapi tidak bermakna secara statistik $(P>0,05)$. Tidak ada efek samping (hipotensi dan bradikardi) pada kedua kelompok.

Kesimpulan: Kami menyimpulkan bahwa Dexmedetomidine 0,2ug/kgBB intravena dapat mengurangi insiden delirium saat pulih sadar dari anestesi umum dengan isofluran pada anak yang menjalani pembedahan elektif.

Kata kunci: dexmedetomidine, delirium, isofluran, anesthesia

\section{PENDAHULUAN}

Kejadian delirium saat pulih sadar pada anak merupakan suatu fenomena bersifat akut yang dapat berhenti sendiri (5-15 menit) namun dapat bertambah parah apabila tidak ditangani dengan segera dan dapat mengakibatkan trauma yang berarti pada anak. ${ }^{1,2}$

Dexmedetomidine merupakan alpha2 reseptor agonis telah banyak dikaitkan dapat menurunkan emergence delirium dengan pemberian dosis tunggal intravena. $^{3}$

Penelitian ini dilakukan untuk membuktikan hipotesis bahwa pemberian dexmedetomidine $0,2 \mathrm{ug} /$ $\mathrm{kgBB}$ intravena dosis tunggal sebelum ekstubasi dapat menurunkan insiden delirium saat pulih sadar dari anestesi umum pada pasien pediatrik yang menjalani prosedur pembedahan dengan anestesi umum dengan gas inhalasi isofluran.

\section{METODE}

Jenis penelitian ini merupakan penelitian acak tersamar ganda. Pada penelitian ini melibatkan 46 pasien anak. Kriteria inklusi meliputi: pasien status fisik ASA I-II, usia 3-10 tahun, akan menjalani pembedahan elektif dengan tehnik anestesi umum, setuju ikut serta dalam penelitian, belum pernah menjalani proses pembedahan sebelumnya, dan ada persetujuan dari dokter primer yang merawatnya. Kriteria ekslusi meliputi riwayat alergi terhadap obat yang digunakan, menderita retardasi mental, menderita gangguan pertumbuhan, menderita penyakit neurologis dan atau 
psikiatrik, adanya gangguan hati dan ginjal.

Ruang lingkup keilmuan: Anestesiologi dan Terapi Intensif Rumah Sakit Wahidin Sudirohusodo Makassar. Ruang lingkup waktu pada bulan Januari sampai Februari 2013. Populasi terjangkau semua pasien yang berumur antara 3-10 tahun di Rumah Sakit Wahidin Sudirohusodo Makassar.

Pasien dibawa ke kamar operasi dan diinduksi dengan sevofluran, jalur intravena dipasang, pasien diberikan premedikasi dengan Sulfat atropin (SA) $0,1 \%$ sebanyak $0,01 \quad \mathrm{mg} / \mathrm{kgBB}$ intravena, fentanyl $1 \mu \mathrm{g} / \mathrm{kgBB}$ kemudian jalan napas diamankan dengan intubasi endotrakeal dengan atrakurium $0,5 \mathrm{mg} /$ $\mathrm{kgBB}$ intravena sebagai pelumpuh otot. Pemeliharaan anestesi dengan isofluran $1-1,5 \mathrm{vol} \%$ dan fentanyl $0,5 \mathrm{ug} / \mathrm{kgBB} / 30$ menit, dan diberikan paracetamol 10 $\mathrm{mg} / \mathrm{kgBB}$ intravena. Pada saat operasi selesai, kelompok perlakuan diberikan dexmedetomidine $\quad 0,2 \quad \mathrm{ug} / \mathrm{kgBB}$ intravena dosis tunggal yang dilarutkan dengan $\mathrm{NaCl} 0,9 \%$ menjadi 5 cc dan diberikan dalam waktu 5 menit dan kelompok kontrol diberikan Nacl 0,9\% (placebo) intravena dengan volume yang sama dan diberikan dalam waktu 5 menit, pasien diekstubasi dan ditransfer ke Post Anesthesia Care Unit (PACU). Di PACU dilakukan pencatatan denyut jantung, Mean arterial presure (MAP), $\mathrm{SpO} 2$, dan skor delirium saat pasien pulih sadar post operasi (PO). Pencatatan secara serial yaitu: P5 (PO + 5 menit), $\mathrm{P} 10$ (P0+10 menit), $\mathrm{P} 15$ (PO + 15 menit) kemudian tiap 15 menit sampai 1 jam.

Skor delirium pada saat pulih sadar dinilai dengan menggunakan skor yang diperkenalkan oleh Watcha dkk. Dan skor nyeri obyektif diukur berdasarkan Hanallah dkk untuk menilai nyeri. ${ }^{4}$

Anak dengan skor 3 atau 4 dinyatakan mempunyai episode delirium pada saat pulih sadar dari anestesi umum. Untuk skor nyeri obyektif, setiap skor dari masing-masing item kemudian dijumlahkan untuk memperoleh nilai total dari OPS (Objectif pain score). Skor OPS < 6 memberi kesan tidak adanya nyeri dan tidak memerlukan pemberian tambahan analgetik, sementara skor $\geq 6$ mengindikasikan pasien dalam keadaan nyeri dan sangat penting untuk memberikan analgetik tambahan. Efek samping berupa hipotensi dan bradikardi serta waktu ekstubasi dan buka mata dicatat.

Data yang diperoleh diolah dan hasilnya ditampilkan dalam bentuk narasi, tabel atau grafik. Analisis statistik menggunakan program SPSS 17 for windows. Data diuji dengan uji $\mathrm{T}$ dan uji Mann Whitney. Tingkat kepercayaan 95\% dan dianggap bermakna bila $\mathrm{p}<$ 0,05 .

\section{HASIL}

Semua pasien digolongkan dengan status gizi : 1. Status gizi buruk dengan IMT (indeks masa tubuh) $<70 \%$, 2. Status gizi kurang dengan IMT 70\%-90\%, 3. Status gizi cukup dengan IMT 90\%$110 \%, 4$. Overweight dengan IMT $110 \%$ $-120 \%$, dan 5. Obesitas dengan IMT $>120 \%$. Sementara untuk jenis 
pembedahan digolongkan menjadi: 1 . Operasi THT, 2. Operasi mata, 3. Operasi orthopedi, 4. Operasi Urologi, dan 5. Operasi bedah umum

Semua pasien yang memenuhi kriteria inklusi dilakukan prosedur pembedahan dengan general anestesi dengan gas anestesi isofluran. Tidak ada perbedaan yang bermakna antara kedua kelompok penelitian dilihat dari jenis karakteristik sampel (Tabel. 3). Didapatkan waktu ekstubasi dan buka mata lebih lama pada kelompok Dexmedetomidine (Tabel. 4) namun tidak bermakna secara statistik (p >0,05). Kestabilan hemodinamik pada kedua kelompok perlakuan tetap terjaga dan tanda vital tetap terpelihara antara 20\% dari tanda vital basal baik saat pemberian obat maupun selama observasi di PACU.

Pada penelitian ini didapatkan pasien yang mengalami episode delirium 1 orang pada Kelompok Dexmedetomidine (D) (4,3\%) dan 11 orang pada Kelompok Salin (S) (47\%) dan hanya 1 orang yang mendapatkan resque midazolam pada Kelompok $\mathrm{S}$ karena skor delirium 4. Dan didapatkan perbedaan yang bermakna $(\mathrm{P}<0,05)$ pada skor pulih sadar dari anestesi umum (ED score) pada setiap waktu observasi. Nilai skor OPS sama pada kedua kelompok ( $p>0,05)$.

Untuk menilai nyeri pascabedah pada sampel kelompok penelitian, peneliti menggunakan skor yang diciptakan oleh Hannalah dkk yang banyak digunakan pada berbagai macam penelitian termasuk juga pada penelitian yang berhubungan dengan delirium. Pada skor ini terdapat 5 kategori yaitu tekanan darah, menangis, pergerakan, agitasi, dan verbal akan nyeri. Dimana masingmasing kategori mempunyai 3 skala penilaian mulai dari 0 sampai 2. Masing masing kategori dinilai dan dijumlahkan untuk mendapatkan skor akhir dan dapat diinterpretasi. Interpretasi dari skor ini terdiri dar 2 parameter yaitu kurang dari 6 yang berarti pasien dinilai tidak nyeri dan lebih atau sama dengan 6 dikatakan nyeri dan dibutuhkan suatu analgetik tambahan. Pada penelitian ini semua sampel baik pada kelompok Dexmedetomidine maupun pada kelompok Saline mempunyai skor nyeri obyektif $<6$ dan tidak bermakna secara statistik. $^{5,6,7}$

\section{PEMBAHASAN}

Penelitian ini memperlihatkan bahwa pemberian Dexmedetomidine 0,2 ug/ $\mathrm{kgBB}$ intravena dosis tunggal sebelum ekstubasi mampu menurunkan insiden dari delirium saat pulih sadar dari anestesi umum pada pasien pediatrik

Delirium saat pulih sadar didefinisikan sebagai suatu keadaan dimana terjadi disosiasi dari kesadaran dimana anak menjadi tidak bisa ditenangkan, cengeng, tidak kooperatif, menangis. ${ }^{2,8}$

Banyak faktor yang diduga dapat mempengaruhi timbulnya delirium saat pulih sadar dari anestesi umum pada pasien pediatrik antara lain kehadiran orang tua pada saat pemulihan. Weldon dkk memperlihatkan bahwa insiden delirium pada saat pulih sadar dari anestesi umum menurun dengan kehadiran orang tua di PACU. Pada 
penelitian ini kami tidak menghadirkan orang tua pasien di PACU untuk menyeragamkan perlakuan pada kedua kelompok penelitian., ${ }^{5,9}$

Jenis operasi juga merupakan faktor yang diduga dapat menjadi faktor risiko munculnya delirium saat pulih sadar dari anestesi umum pada pasien pediatrik. Voepel lewis dkk (2003) melakukan suatu penelitian prospektif yang memperlihatkan bahwa operasi otolaryngologic merupakan faktor risiko independen terhadap kejadian delirium saat pulih sadar dari anestesi umum. Pada penelitian ini, peneliti tidak dapat membuat sampel penelitian mempunyai jenis operasi yang sama karena kurangnya kasus operasi otolaryngologic pada pasien pediatrik di rumah sakit peneliti. Namun dari data penelitian sebaran jenis operasi pada kedua kelompok penelitian dapat dikatakan sama dan tidak bermakna secara statistik. ${ }^{10}$

Nyeri juga dikatakan sebagai faktor risiko munculnya delirium saat pulih sadar dari anestesi umum. Beberapa penelitian telah dilakukan untuk mempelajari efek kausal dari nyeri dan delirium saat pulih sadar dan untuk menurunkan insiden dari delirium saat pulih sadar dari anestesi umum dengan jalan menangani nyeri dengan berbagai modalitas yang berbeda seperti pemberian NSAID dan paracetamol seperti yang dilakukan oleh Gueller dkk. Pada penelitian ini Gueller dkk memberikan analgetik paracetamol. Pada penelitian ini peneliti juga memberikan paracetamol $10 \mathrm{mg} / \mathrm{kgBB}$ intravena intraoperasi yang diharapkan dapat menurunkan risiko faktor nyeri. Selain paracetamol opioid intravena 0,5$1 \mathrm{ug} / \mathrm{kgBB}$ tiap 30 menit intravena juga diberikan untuk menghindari nyeri intraoperatif. Dari penelitian ini faktor nyeri dapat ditekan dimana skor nyeri obyektif pada semua sampel penelitian < 6 dan tidak bermakna secara statistik. ${ }^{4}$

Pemeliharaan anestesi dengan agen inhalasi isofluran dinyatakan mempunyai pengaruh yang sama dalam menimbulkan delirium pada saat pulih sadar dari anestesi umum pada pasien pediatrik dengan gas inhalasi sevofluran. Dimana isofluran dapat meningkatkan kadar norepinefrin dalam tubuh yang merupakan salah satu pemicu terjadinya delirium. ${ }^{11}$

Banyak instrumen atau alat bantu yang digunakan untuk menilai delirium saat pulih sadar dari anestesi umum pada pasien pediatrik antara lain Pediatric anesthesia emergence delirium scale (PAEDS), skor menurut Watcha dkk, dan skor menurut Cravero dkk. Samira dkk (2010) yang meneliti tentang perbandingan skala delirium pada saat pulih sadar dari anestesi umum dengan menggunakan 3 skala yang berbeda yaitu skala PAEDS, skala menurut Watcha, dan skala menurut Cravero, mereka menyimpulkan bahwa ketiga skala yang digunakan masing-masing mempunyai korelasi yang saling berhubungan dan mempunyai keterbatasan masing-masing dalam menilai delirium saat pulih sadar dari anestesi umum. Namun skala menurut Watcha dkk merupakan skala yang paling sederhana yang dapat 
digunakan dalam praktik klinis dan mempunyai sensitivitas dan spesivitas yang lebih tinggi dibandingkan dengan skala yang lain. Oleh karena inilah peneliti memilih skala menurut Watcha karena dianggap paling sederhana dan mudah diterapkan di rumah sakit kami. 12

Dexmedetomidine, seperti halnya $\alpha 2$ adrenoreseptor agonis yang lain mempunyai efek sedasi, anxiolitik, dan analgetik. Efek sedasi didapatkan oleh $\alpha$ 2-adrenoreseptor agonis tidak bergantung secara primer terhadap aktivasi dari $\gamma$-aminobutyric acid (GABA) reseptor, seperti yang dihasilkan oleh sedatif lainnya seperti benzodiazepines dan propofol. Tempat aksi primer dari a 2-adrenoreseptor agonis ini adalah pada locus cereleous bukan pada corteks cerebral. Hal inilah yang menjadi alasan kenapa obat golongan ini menghasilkan jenis sedasi yang berbeda dibandingkan benzodiazepines dan propofol. ${ }^{13}$

Dari hasil penelitian terhadap 2 kelompok sampel penelitian ditemukan adanya perbedaan yang signifikan antara Kelompok Perlakuan dan Kelompok Plasebo $(\mathrm{P}<0,05)$. Hal ini membuktikan bahwa Dexmedetomidine dosis 0,2 ug/ $\mathrm{kgBB}$ dapat menurunkan insiden dari delirium saat pulih sadar dari anestesi umum pada pasien pediatrik, hal ini disebabkan karena Dexmedetomidine mempunyai beberapa efek yaitu efek terhadap aktivasi $\alpha 2$ adrenergik di dorsal horn dan spinal cord yang dapat menghambat pelepasan substansi $\mathrm{P}$ dan akan mengurangi nyeri.
Dexmedetomidine juga mempunyai efek sentral berupa aktivasi pusat vasomotor medula yang akan menurunkan katekolamin sehingga akan dapat mencegah peningkatan katekolamin akibat gas anestesi inhalasi pembedahan, dan proses ekstubasi. Dexmedetomidine mempunyai efek defosforilasi ion chanel yang menurunkan aktivitas neuronal yang akan menyebabkan sedasi dan anxiolitik, juga dapat menstimulasi parasimpatis dan inhibisi simpatis di batang otak sehingga menyebabkan sedasi dan anxiolitik. Efek dari Dexmedetomidine inilah yang merupakan salah satu penyebab waktu ekstubasi dan waktu pulih sadar dari anestesi umum pada Kelompok Perlakuan menjadi lebih lama namun tidak bermakna secara statistik yaitu waktu ekstubasi (p 0,559) dan waktu pulih sadar (p 0,062). Hal ini sesuai dengan penelitian yang dilakukan oleh Gueller dan kawan kawan (2005). Namun berbeda dengan yang ditemukan oleh Ibacache ME (2004) dimana dia melakukan penelitian dengan menggunakan Dexmedetomidine 0,3 ug/ $\mathrm{kgBB}$ dosis tunggal sesaat setelah induksi dan tidak mendapatkan adanya pemanjangan waktu ekstubasi maupun pulih sadar. Hal ini kemungkinan diisebabkan karena adanya perbedaan waktu penyuntikan dexmedetomidine, dimana peneliti menyuntikkan Dexmedetomidine sebelum ekstubasi, sementara Ibacache menyuntikkan Dexmedetomidine sesaat setelah induksi anestesi. $^{4,8,14}$ 
Tabel 1. Skor emergence delirium menurut Watcha dkk

\begin{tabular}{ll}
\hline & \multicolumn{1}{c}{ Skor } \\
\hline 0 & Anak tidur \\
\hline 1 & Anak tenang \\
\hline 2 & Anak menangis tapi masih dapat \\
\hline 3 & \\
\hline 4 & Anak menangis dan susah ditenangkan \\
\hline
\end{tabular}

Tabel 2. Skor nyeri obyektif berdasarkan Hanallah dkk

\begin{tabular}{llc}
\hline \multicolumn{1}{c}{ Observasi } & \multicolumn{1}{c}{ Kriteria } & Poin \\
\hline Tekanan darah & 10\% dari nilai basal & 0 \\
& $>20 \%$ dari nilai basal & 1 \\
& $>30 \%$ dari nilai basal & 2 \\
\hline Menangis & Tidak menangis & 0 \\
& Menangis, namun berhenti dengan bujukan & 1 \\
& Menangis, dan tidak berhenti dengan bujukan & \\
& & 2 \\
\hline Pergerakan & Tidak ada & 0 \\
& Gelisah & 1 \\
& Tak terkendali & 2 \\
\hline Agitasi & Tidur atau tenang & 0 \\
& Agitasi ringan & 1 \\
& Histeria & 0 \\
\hline Verbal akan nyeri & Tidur atau tanpa keluhan nyeri & 1 \\
& Mengeluh ada nyeri namun tidak bisa & \\
& menunjukkan & 2 \\
\hline
\end{tabular}


Tabel 3. Karakteristik Sampel

\begin{tabular}{lccc}
\hline \multicolumn{1}{c}{ Parameter } & $\begin{array}{c}\text { Kelompok D } \\
(\mathbf{n = 2 3})\end{array}$ & $\begin{array}{c}\text { Kelompok S } \\
(\mathbf{n = 2 3})\end{array}$ & $\boldsymbol{P}$ \\
\hline${\text { Umur (tahun })^{1}}^{\prime}$ & $7,17 \pm 2,146$ & $7,17 \pm 2,289$ & 1,000 \\
\hline Jenis kelamin (L/P) & $15 / 8$ & $18 / 5$ & 0,526 \\
\hline ASA PS (I/II) & $2 / 21$ & $3 / 20$ & 0,386 \\
\hline Status gizi (1/2/3/4/5) & $0 / 2 / 20 / 1 / 0$ & $0 / 2 / 20 / 1 / 0$ & 1,000 \\
\hline Durasi operasi (menit) & 1 & $80,96 \pm 21,438$ & 0,458 \\
\hline Jenis operasi $(1 / 2 / 3 / 4 / 5)^{2}$ & $2 / 4 / 6 / 7 / 4$ & $2 / 3 / 6 / 8 / 4$ & 0,451 \\
\hline
\end{tabular}

${ }^{1}$ Uji t - independent, ${ }^{2}$ uji mann - whitney U

Keterangan: Kelompok D = Kelompok Dexmedetomidine, Kelompok S = Kelompok Saline

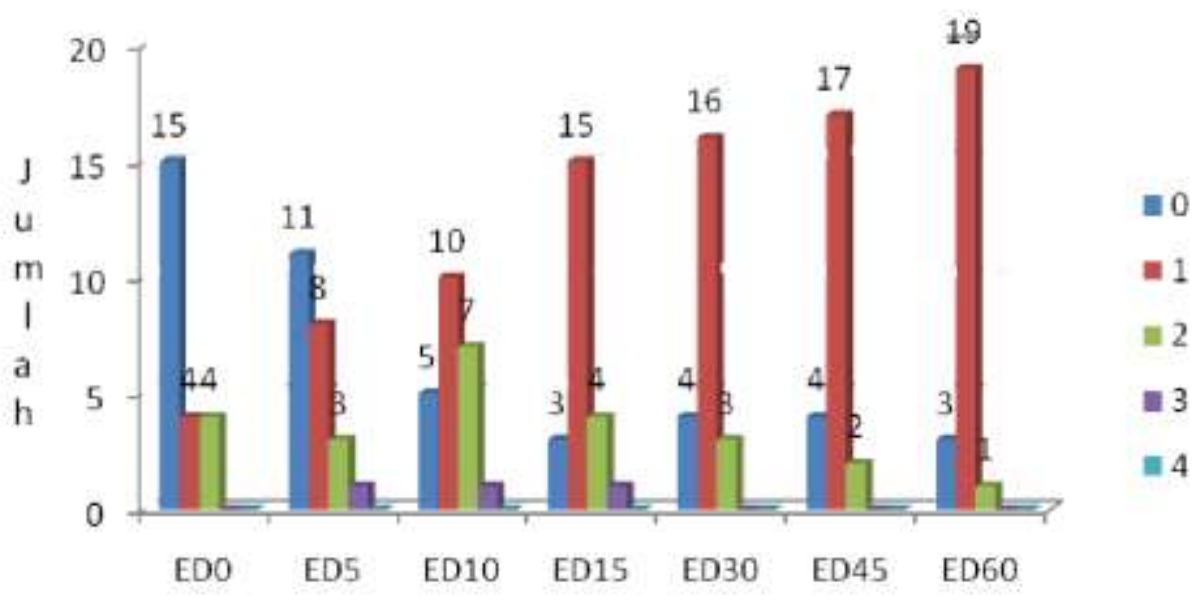

Waktu observasi

Gambar 1. Hubungan antara waktu pengamatan dengan jumlah pasien dengan tingkat delirium masing-masing pada kelompok Dexmedetomidine, pada grafik ini dapat dilihat pada setiap waktu observasi sebagian besar sampel memiliki skala 0 sampai 1, hanya 1 orang yang memiliki skala 3 . 


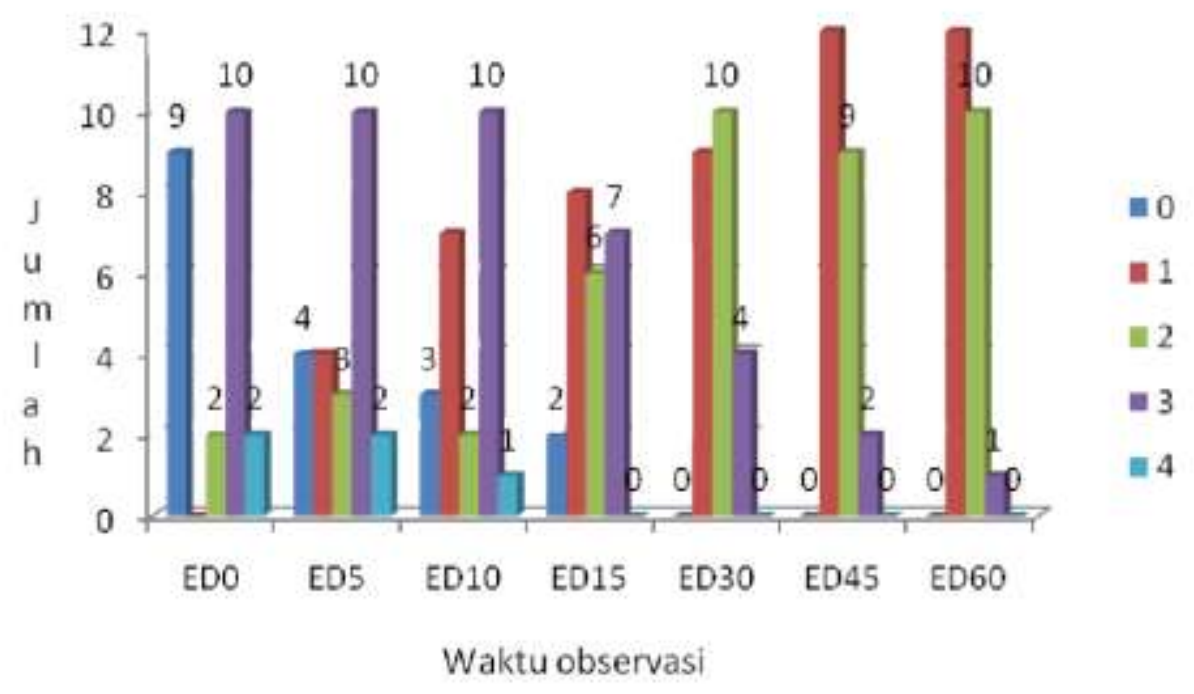

Gambar 2. Hubungan antara waktu pengamatan dengan jumlah pasien dengan tingkat delirium masing-masing pada kelompok kontrol, pada grafik ini dapat dilihat sebagian pasien pada awal waktu observasi (sampai P 15) memiliki ED score $\geq 3$.

Tabel 4. Penilaian nyeri objektif pascabedah

\begin{tabular}{lccccc}
\hline \multirow{2}{*}{ Variabel } & \multicolumn{2}{c}{ Kelompok D } & \multicolumn{2}{c}{ Kelompok S } & $\boldsymbol{p}$ \\
\cline { 2 - 4 } OPS0 & $\mathbf{6} 6$ & $\mathbf{2} \mathbf{6}$ & $\mathbf{< 6}$ & $\mathbf{2 6}$ & \\
\hline OPS5 & 23 & 0 & 23 & 0 & 1,000 \\
OPS10 & 23 & 0 & 23 & 0 & 1,000 \\
OPS15 & 23 & 0 & 23 & 0 & 1,000 \\
OPS30 & 23 & 0 & 23 & 0 & 1,000 \\
OPS45 & 23 & 0 & 23 & 0 & 1,000 \\
OPS60 & 23 & 0 & 23 & 0 & 1,000 \\
\hline
\end{tabular}

*Uji mann-whitney; p>0,05 dinyatakan tidak bermakna pada setiap waktu observasi 
Tabel 5. Waktu ekstubasi dan pulih sadar

\begin{tabular}{cccc}
\hline Variabel & $\begin{array}{l}\text { Kelompok D } \\
(\text { mean } \pm \text { SD) }\end{array}$ & $\begin{array}{l}\text { Kelompok S } \\
(\text { mean } \pm \text { SD) }\end{array}$ & $P$ \\
\hline Waktu ekstubasi & $8,26=1,936$ & $7,91=2,065$ & 0,559 \\
Waktu pulih sadar & $12,65=2,080$ & $11,30=2,653$ & 0,062 \\
\hline
\end{tabular}

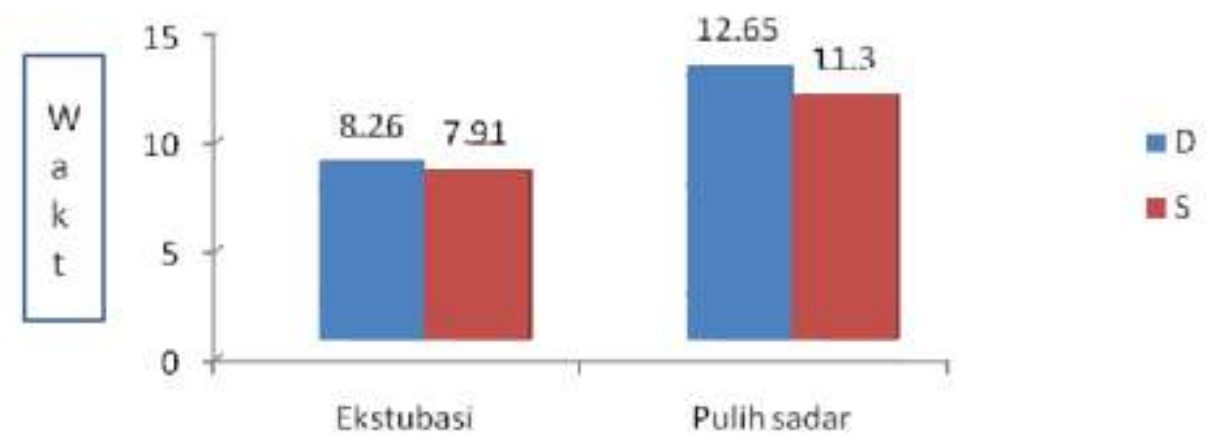

Gambar 3. Grafik waktu ekstubasi dan pulih sadar dari anestesi umum antara kelompok Dexmedetomidine (D) dan kelompok Saline (S) yang tidak bermakna secara statistik 


\section{SIMPULAN}

Insiden kejadian delirium pada saat pulih sadar dari anestesi umum pada pasien pediatrik lebih rendah pada kelompok Dexmedetomidine 0,2 ug/ $\mathrm{kgBB}$ intravena dosis tunggal sebelum ekstubasi dibandingkan dengan kelompok normal saline $0,9 \%$, waktu ekstubasi dan waktu pulih sadar dari anestesi umum pada pasien pediatrik pada kelompok Dexmedetomidine 0,2 ug/kgBB lebih lama secara klinis namun tidak bermakna secara statistik, dan tidak ditemukan adanya efek samping berupa hipotensi dan bradikardi dengan pemberian Dexmedetomidine 0,2 ug/ $\mathrm{kgBB}$ intravena dosis tunggal.

\section{DAFTAR PUSTAKA}

1. Lewis TV, Malviya S. A prospective cohort study of emergence agitation in the pediatric postanesthesia care unit. Anesth Analg 2003;96:1625-30.

2. Mason LJ. Emergece delirium. In: Pitfalls of pediatric anesthesia, New York: Loma Linda University Publisher;2010.p.1505.

3. Guler G, Akin A, Tosun Z, Ors S, Esmaoglu A, Boyaci A. Singledose dexmedetomidine reduces agitation and provides smooth extubation after pediatric adenotonsillectomy. Pediatric Anesthesia 2005;15:762-6

4. Syukry M, Cain JG. Dexmedetomidine prevents and treats agitation, delirium, and withdrawl. Int $\mathbf{J}$ Trauma $2007 ; 17$ (1):24-6.

5. Ibacache ME, Munoz HR, Brandez V, Morales AR. Single dose dexmedetomidine reduce agitation after sevofluran anesthesia in children. Anesth Analg 2004;98(1):60-63.

6. Malviya S. Assessment of pain in children. Presennted at SPA annual meeting. 2006: 3-6

7. McClain BC. Newer modalities for pain managements. Presented at SPA Annual Meeting. 2006: 1-6.

8. Mountain BW, Smithson L, Cramolini M, Wyatt TH, Newman M. Dexmedetomidine as a pediatric anesthetic premedication to reduce anxiety and to deter emergence delirium. AANA J 2011;79(3):219-23.

9. Weldon BC, Watcha MF, White PF. Oral midazolam in children: effect of time and adjunctive theraphy. Anesth Analg 1992;75(5) 51-55.

10. Mountain BW, Smithson L, Cramolini M, Wyatt TH, Newman M. Dexmedetomidine as a pediatric anesthetic premedication to reduce anxiety and to deter emergence delirium. AANA $\mathbf{J}$ 2011;79(3):219-23.

11. Meyer RR, Munster P, Werner C, Barmbrink AM. Isofluran is associated with a similar incidence of agitation/delirium as sevofluran in young children: a randomised controlled study. Pediatr Anesth 2007;17(1):56-60

12. Samira A, Bajwa FR, Fanzcha DC, Allan M. A Comparison of emergence delirium scales following general anesthesia in children. Pediatr Anaesth J 2010;20(8):704-11

13. Tobias JD. Dexmedetomidine: Applications in pediatric critical care and pediatric anesthesiology. Pediatr Crit Care Med 2007;8:115131

14. Aarts A, Hagen VV, Russchen H. Does pharmacologic treatment 
prevent children from emergence agitation after sevofluran anesthesia? a systematic review. Eras J Med 2012;2(2):24-8. 